VARIA

\title{
A questão do sentido e do sagrado na modernidade
}

\section{The question of meaning and sacred in modernity}

* Marcelo Perine

Em memória de João Batista Libanio, SJ (1932-2014)

\begin{abstract}
Resumo: O texto parte de uma compreensão da modernidade nos termos de uma virada antropológica, que caracteriza a cultura ocidental a partir do século XVII. As figuras de Descartes e de Hobbes assinalam, respectivamente, a descoberta da subjetividade e do indivíduo. Em seguida, reflete sobre o problema de Deus no discurso filosófico: a atitude da fé é tematizada na compreensão do homem como imagem de Deus e do mundo como estrutura racional teleologicamente ordenada para Deus. Finalmente, o texto propõe a compreensão da experiência religiosa e da contingência nos termos de uma experiência do sentido, pela qual o ser humano pode abrir-se para a atitude da fé radical como reconhecimento do que dá sentido à existência de cada um.
\end{abstract}

Palavras-chave: Modernidade. Virada antropológica. Deus. Fé. Contingência. Sentido.

\begin{abstract}
The paper begins with an understanding of modernity in terms of an anthropological turn that characterizes Western culture from the seventeenth century. The figures of Descartes and Hobbes indicate, respectively, the discovery of subjectivity and the invention of the individual. Then reflects on the problem of God in philosophical discourse: the attitude of faith is thematized in the understanding of man as image of God and the world as rational structure teleologically ordered toward God. Finally, the paper proposes the understanding of religious experience and of human contingency in terms of an experience of meaning, in which the human being can open himself to the attitude of radical faith as recognition of what gives meaning to the existence of each.
\end{abstract}

Keywords: Modernity. Anthropological turn. God. Faith. Contingency. Meaning.

* Professor Associado da PUC/SP. Bolsista de produtividade do CNPq. <mperine@gmail.com>. Este texto foi apresentado como Aula inaugural do ano acadêmico de 2014 dos Programas de Pós-Graduação em Filosofia e em Teologia da Pontifícia Universidade Católica do Rio Grande do Sul. 


\section{A nossa modernidade e suas origens}

I omeço com um esclarecimento sobre o conceito de modernidade. Por modernidade, entendo aqui tanto um período histórico da tradição ocidental iniciado no século XVII, como um fenômeno típico dessa mesma tradição, que pode ser definido como "virada antropocêntrica". ${ }^{1}$

Na tradição cultural do ocidente, a modernidade tem data de nascimento perfeitamente determinável e pelo menos dois pais inequivocamente identificáveis. Pode-se datar o início da nossa modernidade no ano em que Descartes escreveu as Regulae ad directionem ingenii, isto é, em 1629, muito embora a obra só tenha sido publicada depois da morte do filósofo. ${ }^{2}$ Ao estabelecer a data do nascimento, identifica-se também um dos pais da modernidade: René Descartes (1596-1650), cuja obra mais famosa é o Discurso do método (1637), imortalizada pela fórmula "penso, logo existo".

Entretanto, a paternidade da modernidade ocidental deve ser atribuída também ao filósofo inglês Thomas Hobbes (1588-1679), com quem note-se - Descartes manteve uma fecunda correspondência epistolar. Hobbes publicou uma obra revolucionária chamada Leviatã (1651), que imortalizou a fórmula "o homem é lobo do homem". Curiosamente, esta fórmula hobbesiana que se refere ao hipotético estado de natureza ou de guerra de todos contra todos, no último diálogo escrito por Platão é apresentada como constitutiva do estado civil. De fato, logo no início do diálogo As Leis, Clínias, o interlocutor do Ateniense, reconhece que é correta a afirmação de quem "sustentou que na dimensão política todos são inimigos de todos e na dimensão privada cada um está em conflito consigo mesmo". ${ }^{3}$

Hobbes pode ser considerado um dos fundadores da modernidade no campo da ética por força de sua radical rejeição do princípio estruturador da ética antiga e da ética medieval, a saber, a ideia do Bem, para os antigos, e Deus, para os medievais, como o fim último da ação humana. Na trilha já aberta por Maquiavel, para quem "todos os homens são maus e dispostos a usar a própria perversidade todas as vezes que encontram ocasião propícia", ${ }^{4}$ Hobbes é o primeiro a propor um fim estritamente egoísta e utilitarista para a ética: o móvel das ações humanas é o

1 Uma exaustiva exposição das "raízes da modernidade" pode ser encontrada em: LIMA VAZ, H. C. de, Escritos de filosofia VII. Raízes da modernidade, São Paulo 2002.

2 Cf. LIMA VAZ, H. C. de, Religião e modernidade filosófica, Síntese Nova Fase (Belo Horizonte), v. XVIII, n. 53, abr.-jun. 1991, p. 155.

3 Cf. PLATÃo, Leis, I, 626 D.

4 Cf. MAQUIAVEL, Discursos sobre a primeira década de Tito Lívio, Livro I, capítulo III. Também no capítulo XVII de O príncipe, Maquiavel afirma que os homens "são ingratos, volúveis, simuladores, covardes ante os perigos, ávidos de lucro". 
instinto de autoconservação e dominação. No âmbito da ação, a razão atua apenas como calculadora dos meios a serem utilizados em vista da conservação da própria vida. O seu antropocentrismo radical no campo da ética é determinante também no campo do direito. Partindo da hipótese metodológica do estado de natureza, Hobbes demonstra que a sociedade civil é fruto de um cálculo que, por um processo mecânico de transferência de direitos e de delegação de poder, produz o "homem artificial" ou a "pessoa civil" ou, ainda, o "deus mortal", que é o Estado, fruto de um contrato realizado pela totalidade dos indivíduos. ${ }^{5}$

Assim, a grande "descoberta do homem", que caracteriza o século XVII, aparece também na revolução galileana da doutrina jurídica operada por Hobbes: ao descartar todo princípio teológico e transcendente, ele sublinha que a soberania pertence essencialmente ao universo profano e, portanto, que a essência da política não se encontra no céu, mas na terra. ${ }^{6}$ Em suma, para Hobbes, existe uma perfeita equação entre moral, social, contratual ou convencional. O homem, ou melhor, o indivíduo está na origem de tudo o que tem valor e, portanto, de tudo que é digno de respeito.

A figura de Descartes é quase um ícone das profundas transformações que começaram a ocorrer no Ocidente a partir do século XVII. A obra de Descartes produziu uma total reestruturação do universo mental do Ocidente a partir da inversão provocada pela certeza primeira do "eu penso" guiada pelas regras do método. Temos aqui uma das maiores expressões da "virada antropocêntrica" característica do século XVII, que, curiosamente, também foi marcado por intensa espiritualidade mística centrada na ideia agostiniana do "homem interior", ${ }^{7}$ da qual a obra de Blaise Pascal (1623-1662) é uma das expressões mais refinadas. ${ }^{8}$ Entretanto, em contraste com a concepção pascaliana, a introspecção cartesiana estava marcada por uma tensão interna, que pode ser designada pela oposição entre imanência e transcendência. Embora Descartes tenha optado decididamente pela transcendência, o que implica, em termos morais, "a irredutibilidade da liberdade à razão e a soberania absoluta da Liberdade infinita sobre a ordem das razões", ${ }^{9}$ a outra vertente da ética moderna, traçada pelo imanentismo radical de

5 Sobre a concepção hobbesiana da moral e da política, ver a excelente síntese de: LIMA VAZ, H. C. de, Escritos de filosofia IV. Introdução à Ética filosófica I, São Paulo 1999, p. 293-311.

6 Ver melhor esse ponto em GOYARD-FABRE, S., Introduction à Le citoyen ou les fondements de la politique, trad. S. Sorbiere, Paris 1982, p. 33-44.

7 Ver a respeito KOLAKOWSKI, L., Chrétiens sans église: la conscience religieuse et le lien confessionel au XVII ème siècle, Paris 1969.

8 Sobre a caracterização da antropologia pascaliana no interior da tradição agostiniana, cf. PRZYWARA, E., Augustin: passions et destin de l'Occident, trad. P. Sécretan, Paris 1987, p. 49-53.

9 Cf. LIMA VAZ, H. C. de, Escritos de filosofia IV, op. cit., p. 288. 
Hobbes, não conduzia ao fundamento divino do ser, mas encontrava no eu pensante o seu estágio final. ${ }^{10}$

Como observou Hannah Arendt, a partir de Descartes, a dúvida passou a ocupar, na filosofia ocidental, a mesma posição central que, desde os gregos, tinha sido ocupada pela admiração diante de tudo o que existe. Dado que a dúvida, para Descartes, podia ser estendida à totalidade da realidade, não escapando dela nem mesmo a experiência do pensamento, seguia-se que a certeza de existir pelo fato de pensar - esse é o sentido do cogito ergo sum - podia ser reduzida à certeza de duvidar. ${ }^{11}$ Aqui também a grande "descoberta do homem", iniciada tentativamente no século XVI com a chamada "revolução copernicana" nas ciências, operou uma revolução. A descoberta da subjetividade, que é o cerne da revolução cartesiana, realizou, malgré soi, ${ }^{12}$ uma recentração metafísica do ser humano como ser-no-mundo, situando-o como sujeito no centro do universo inteligível. ${ }^{13}$ A revolução cartesiana marca uma profunda ruptura no modo de pensar: a estrutura ontoteológica é substituída por uma estrutura ontoantropológica, ${ }^{14}$ ou, o que é o mesmo, a teologia é imanentizada na ontologia do sujeito humano. ${ }^{15}$ Ao imanentizar o fundamento de toda a realidade, o interesse da razão volta-se "para a imanência da História, da Natureza e do próprio Homem". ${ }^{16}$

\section{O problema de Deus e sua raiz filosófica}

Objeto da fé religiosa, Deus entrou no discurso filosófico não só porque a filosofia tentou transpor para o registro da razão demonstrativa as certezas da idade pré-racional, mas também porque, em última análise, a fé é uma das atitudes possíveis ao ser humano no mundo e porque ela foi uma atitude efetivamente vivida pelo ser humano na história. Na atitude da fé, o ser humano compreendeu-se como humano e, ao explicitar essa compreensão de si mesmo num discurso coerente, acabou explicitando uma nova categoria do discurso filosófico. Nessa categoria, o ser humano compreendeu-se em Deus, como imagem e semelhança dele e, portanto, não só como razão, mas também como liberdade ${ }^{17}$.

10 Cf. KOLAKOWSKI, L., Metaphysical horror, Oxford 1988, p. 66-67.

11 Cf. ARENDT, H., A condição humana, Rio de Janeiro 1991, p. 286-292.

12 Sobre a polêmica em torno da questão da orientação metafísica do pensamento cartesiano após 1637, ver: LIMA VAZ, H. C. de, Escritos de filosofia IV, op. cit., p. 285 ss.

13 Cf. LIMA VAZ, H. C. de, Antropologia Filosófica I, São Paulo 1991, p. 263.

14 Cf. LIMA VAZ, H. C. de, Religião e modernidade filosófica, art. cit., p. 154 s.

15 Cf. LIMA VAZ, H. C. de, Antropologia Filosófica I, op. cit., p. 261.

16 Cf. LIMA VAZ, H. C. de, Antropologia Filosófica II, São Paulo 1992, p. 115.

17 Sobre Deus como categoria do discurso filosófico, cf. WEIL, E., Lógica da filosofia, trad. Lara C. de Malimpensa, rev. téc. M. Perine, São Paulo, 2012, p. 249-286. 
A tradição filosófica ocidental, cuja origem remonta às proposições fundadoras de Tales de Mileto, compreendeu o universo nos termos de uma estrutura racional, que foi traduzida na época do neoplatonismo pelo esquema de processão e retorno, ou seja, tudo procede de um Primeiro Princípio ao qual tudo retoma. Ora, esse esquema, que encontrou a sua, talvez, mais brilhante formulação na obra de Plotino, traduz a matriz teológica que está na base do pensamento filosófico desde os présocráticos, e que se manterá inalterada até Kant. ${ }^{18}$

O pressuposto ontológico e epistemológico de todo esse ciclo de pensamento é que o mundo pode ser pensado como uma grandeza teológica, independentemente de ser concebido ou não como obra de Deus. Isso significa que mesmo pensadores considerados "ateus" como, por exemplo, Epicuro, apoiaram-se sobre esse pressuposto. Para todos os pensadores da filosofia antiga e medieval, e até mesmo para muitos filósofos do início da era moderna, o espaço do mundo apresentava-se como um espaço teológico, ordenado para um centro absoluto, fosse ele chamado de Primeiro Princípio, Movente Imóvel ou Deus Criador, do qual procedem a inteligibilidade e o ser do mundo.

Isso explica porque entre as assim chamadas "provas" da existência de Deus, as de caráter cosmológico tiveram, desde a Antiguidade, uma autoridade superior às outras. É esse pressuposto ontológicoepistemológico que permite entender porque São Tomás de Aquino criticou o famosíssimo "argumento ontológico" de Santo Anselmo, formulado no Proslogium. ${ }^{19}$ De fato, nas famosas "cinco vias" desenvolvidas no $3^{\circ}$ artigo da $2^{\mathrm{a}}$ questão da primeira parte da Suma Teológica, São Tomás trabalha fundamentalmente com argumentos cosmológicos, e a prova dominadora é, justamente, a primeira, conhecida como a prova ex motu, isto é, "pelo movimento". 20

${ }_{18}$ Em denso artigo sobre o problema de Deus no pensamento contemporâneo, afirma Henrique C. de Lima Vaz: Ao contrário do que habitualmente se pensa, a filosofia e a ciência não surgiram como uma crítica ou uma rejeição ao mito. A filosofia é, ao invés, herdeira do mito. Ela foi a tentativa de transpor para o registro da razão, o registro do logos demonstrativo, a visão do mundo que alimentou as certezas do homem na idade pré-racional. Com efeito, na origem do pensamento filosófico que, com seus primeiros passos, se confundia com o pensamento científico, estava presente o esforço para impedir que desmoronassem, de modo irremediável, a coerência e a significação do universo construído pela religião e pelo mito". Cf. LIMA VAZ, H. C. de, O problema de Deus no pensamento contemporâneo, Síntese Nova Fase (Belo Horizonte), v. VIII, n. 23, set.-dez. 1981, p. 18.

19 Sobre a crítica de Tomás de Aquino a Santo Anselmo, ver: XAVIER, M. L. L. O., O argumento anselmiano entre continuadores e críticos, in: XAVIER, M. L. L. O., A questão de Deus na história da filosofia, v. 1, Sintra 2008, p. 269-326, espec. p. 288-293.

20 Cf. TOMÁS DE AQUINO, Suma Teológica, I, q. 2, a. 3. Sobre isso ver: BOLINHAS, M. I., Uma releitura das cinco vias de Tomás de Aquino à luz do conceito de ser, in: XAVIER, M. L. L. O., A questão de Deus na história da filosofia, v. 1, Sintra 2008, p. 327-349. 
Mesmo para filósofos modernos como Descartes e Espinosa, o problema filosófico por excelência era o problema de uma explicação radical do mundo a partir do próprio mundo. Ora, explicar radicalmente o mundo para a filosofia pré-kantiana era dar a razão da exigência de fundamentação racional do mundo num Princípio Absoluto, que, segundo São Tomás de Aquino, "chamamos Deus". Porém, o momento racional da fé na obra de São Tomás não se inscreve nos quadros de uma teodiceia, isto é, de uma justificação de Deus diante do homem. Ao contrário, o momento racional da fé circunscreve o campo de uma filosofia autônoma, que não mistura a água da razão com o vinho da revelação, mas opera a transformação da água em vinho. ${ }^{21}$ Ao mesmo tempo fiel a Santo Agostinho, mas o superando nas suas versões platonizantes, e compreendendo Aristóteles melhor do que ele foi compreendido nas malhas avicenizantes, São Tomás não pretendeu saber o que é Deus ou defini-lo em função do mundo ou do homem, mas quis compreender a última raiz de inteligibilidade do universo revelável. Ora, a raiz da inteligibilidade do universo encontra-se na própria gratuidade advinda do ato de existir, proporcional, não à necessidade de um princípio incondicionado, mas à gratuidade absoluta do Amor. Dito de outro modo, a inteligibilidade última de todo o real revela-se na relação de criação, que é a criação da relação.

Nos tempos modernos, a partir de Descartes, ocorre uma importante modificação nos dados do problema, mesmo que não tenha atingido a natureza profunda do problema. ${ }^{22}$ Com o surgimento da filosofia da subjetividade, a matriz de inteligibilidade desloca-se do mundo para o sujeito conhecente. Até Descartes, vigorava o postulado implícito a todo pensamento filosófico de que a razão humana tinha uma relação de homologia com o Universo. O fundamento dessa homologia entre a razão e o Universo era encontrado no Primeiro Princípio como Inteligência primeira, na qual o Universo é pensado e existe, e da qual jorra para a inteligência humana a luz sob a qual se compreende o Universo e a sua relação com a razão humana.

A filosofia da subjetividade estabelece uma nova relação entre o mundo e a razão humana. Cabe à própria razão estabelecer um código próprio para poder decifrar o mundo. A revolução científica moderna,

${ }^{21}$ Cf. TOMÁS DE AQUINO, In Boet. De Trin., 2, 3, 5: "Et tamen potest dici, quod quando alterum duorurn (aquae et vini) transit in dorninium alterius, non reputatur mixtio; sed quando utrumque a sua natura alteratur. Unde illi qui utuntur philosophicis documentis in sacra doctrina redigendo in obsequium fidei, non miscent aquam vino, sed aquam in vinum convertunt".

22 Sobre esse desenvolvimento cf. SEVE, B., La question philosophique de l'existence de Dieu, $2^{\text {ème }}$ éd. revue, Paris 1997. Ver também PENZO, G.; GIBELINI, R., Deus na filosofia do século XX, trad. R. Leal Ferreira, São Paulo 1998, p. 13-21. 
a partir de Galileu, ilustre contemporâneo de Descartes, introduz uma mediação empírico-formal na relação da razão com o mundo, até então admitida como relação imediata de homologia. A partir daí, constitui-se um novo regime epistemológico de leitura dos fenômenos, no qual se acentua progressivamente a atividade do homem no estabelecimento de códigos admitidos como válidos para a leitura e decifração do mundo. Os códigos de leitura, como estabeleceu Descartes em seu "método", são de natureza matemática. Também para Galileu, o livro da natureza estava escrito em caracteres matemáticos e isso impunha a necessidade de aprender essa linguagem para entender aquele livro.

Com a filosofia do sujeito, o problema de Deus não se situa mais no prolongamento da homologia imediata entre a razão e o mundo, mas no terreno da própria razão, no qual, a partir de então, surge a necessidade de fundamentar a nova ciência do mundo construída pelo homem. Por isso, entende-se que Descartes, ao retomar as provas da existência de Deus, tenha conferido ao "argumento ontológico" o caráter de argumento dominador, justamente porque esse argumento suprime a mediação do mundo na passagem da razão a Deus. ${ }^{23}$

A partir da modernidade, a razão passa a ser o polo de inteligibilidade do mundo e o centro do sistema de inteligibilidade científica. A ciência moderna acabou por elaborar um novo conceito de natureza, a partir do qual se reformulou o código de leitura do mundo. Tendo realizado a "revolução copernicana", que consistiu em colocar o centro de inteligibilidade do universo na razão humana, a ciência moderna caminhou rapidamente na direção de tornar dispensável a "hipótese Deus", como afirmou Laplace, para a compreensão do mundo.

$\mathrm{Na}$ aurora da nossa contemporaneidade filosófica, Kant transpõe o problema de Deus para o plano da liberdade, isto é, para o plano da "razão prática". Se não pode ser provado pela razão teórica, ${ }^{24}$ Deus pode

${ }^{23}$ Segundo Emerich Coreth, "A questão de Deus assume no pensamento de Descartes uma posição fundamental, pois toda a verdade e toda a certeza fundam-se na veracidade de Deus. Na medida em que Deus não é demonstrável a partir da experiência deste mundo - entendido de modo mecanicista -, Descartes refugia-se na idea innata Dei. Acolhe assim uma antiga tradição do pensamento inato de Deus, porém entendendo-o racionalisticamente como ideia 'clara e distinta', que precisamente enquanto tal não é demonstrável. A partir desta decorrem todas as suas demonstrações da existência de Deus, que sob este pressuposto permanecem questionáveis. Testemunham, no entanto, que todo o sistema de Descartes sustenta-se e cai com o conhecimento de Deus. Sem este nada é verdadeiramente cognoscível e explicável. Dessa maneira, também Descartes torna-se um testemunho de Deus nos primórdios do pensamento filosófico da Idade Moderna". Cf. CORETH, E., Deus no pensamento filosófico, trad. F. de A. Pinheiro Machado, São Paulo 2009, p. 208 s.

24 Sobre a "desmontagem das provas especulativas da existência de Deus", ver: LONGLOIS, L., O fim das coisas e o fim da liberdade: a ideia de Deus na Crítica da razão pura, in: LONGLOIS, L.; ZARKA, Y. C., Os filósofos e a questão de Deus, trad. L. P. Rouanet, São Paulo 2009, p. 199220, espec. p. 202-212. 
ser postulado pela razão prática e, se há alguma prova possível de sua existência, esta só pode ser uma "prova moral". A partir de Kant, com o predomínio da razão prática no centro das preocupações do universo filosófico, a filosofia do sujeito caminhou, segundo a sua lógica interna, na direção da filosofia da história. Para esta, o campo próprio da reflexão filosófica não é mais o Universo, reduzido à sua materialidade, mas a ação humana na sua dimensão histórica. A liberdade ou, o que é o mesmo, a práxis histórica do ser humano torna-se o problema central da filosofia.

É nesse campo que se vai travar a última grande batalha filosófica em torno da questão de Deus. Para Hegel, em suas Lições sobre a filosofia da história, a História, como campo da liberdade, é a verdadeira teodiceia. O termo "teodiceia", que, literalmente, significa "justificação de Deus", fora introduzido por Leibniz para designar a ciência que traçaria o novo caminho para Deus a partir de uma nova harmonia entre o homem e o Universo. Segundo Hegel, esse caminho é a própria História como lugar da verdadeira teodiceia. Do mesmo modo em que a razão humana tomou o lugar do mundo como grandeza teológica no início da modernidade, agora, no início da nossa contemporaneidade filosófica, é a história que substitui o mundo porque o problema do sentido absoluto inscreve-se no contexto da práxis histórica humana. A filosofia de Hegel, segundo Lima Vaz, apresenta-se

[c]omo um esforço titânico para restaurar, no terreno da História, a teologia dos antigos filósofos, que se elevara sobre o terreno da Natureza. A História é uma 'Teodiceia'. A justificação de Deus nela está presente como exigência de explicação racional dos seus múltiplos sentidos que culminam, para Hegel, na existência de um sentido absoluto (que ele denomina Espírito Absoluto). A História não é senão o itinerário, que pode ser descrito dialeticamente, do saber de si mesmo que se eleva ao Saber absoluto, e, nele, à epifania histórica de Deus. ${ }^{25}$

Depois da tentativa hegeliana de fazer da história a prova da existência de Deus, uma nova guinada acabaria por excluir o último reduto da uma possível teologia natural. Ao longo do século XIX, as críticas de Karl MarX e de Augusto Comte pretenderam excluir o problema do Fundamento do terreno das explicações da história e da sociedade. O processo histórico foi afirmado como autoexplicativo, tendo como único ator e único fundamento o próprio ser humano. Assim, o teocentrismo, inicialmente, cósmico e, depois, histórico cedeu lugar ao antropocentrismo histórico.

Ao lado da crítica de Marx, formulou-se, também no século XIX, uma das mais radicais reflexões sobre a cultura e sobre a vida, e uma das

$\overline{25}$ Cf. LIMA VAZ, H. C. de, O problema de Deus no pensamento contemporâneo, art. cit., p. 25. 
mais contundentes críticas do cristianismo já formuladas no discurso filosófico. A obra de Nietzsche representa, no âmbito da fundamentação dos valores, um abalo equivalente ao que representou a obra de Kant no âmbito da fundamentação do conhecimento. A grande interrogação que atravessa a obra devastadora de Nietzsche é: o que significa para o ser humano o mundo da cultura e qual o significado da vida, entendida como "vontade de potência", como valor fundamental? Nesse contexto, Nietzsche retomou a proclamação da "morte de Deus", conferindo-lhe um alcance muito maior do que o que tivera na literatura romântica alemã daquele tempo. Para Nietzsche, a única possibilidade de afirmar a vida como criação de valores é negar o valor Transcendente, chamado Deus pela tradição monoteísta do Ocidente. Mais ainda, segundo Nietzsche, esse dinamismo negador da Transcendência estaria inscrito na própria dinâmica de afirmação da vida como vontade de potência. ${ }^{26}$

Depois de Nietzsche, que morreu na aurora do século XX, as grandes discussões do problema de Deus foram desencadeadas no âmbito do problema da fundamentação da liberdade, que dominou a filosofia na primeira parte do século XX. Uma das expressões radicais dessa discussão é a obra de Jean-Paul Sartre, na qual o problema do fundamento é transposto para o campo da decisão, na medida em que o ser humano é definido como liberdade existencial, isto é, como liberdade que se encontra lançada no mundo sem ser coisa do mundo. Ora, o fato de serpara-si encerra, para o ser humano, o contraditório e, por isso mesmo, impossível projeto de tornar-se ser-em-si, isto é, de tornar-se Deus. Para Sartre, o absurdo da existência humana é, exatamente, o projeto de ser Deus, isto é, de fundar radicalmente a própria liberdade sem, contudo, poder fazê-lo. Segundo Sartre, assumir a finitude da própria liberdade é o primeiro passo de um ateísmo que reduz o problema de Deus a um problema sem sentido e, portanto, sem necessidade de solução. ${ }^{27}$

Sobre o filósofo alemão Martin Heidegger, que marcou decisivamente o pensamento filosófico contemporâneo a partir dos anos 20 do século passado, remeto a um texto que publiquei na Revista Síntese em 1993, republicado no volume Eric Weil e a compreensão do nosso tempo, ${ }^{28}$ no

${ }^{26}$ Sobre a questão de Deus na obra de Nietzsche ver: RICARD, M.-A., A morte de Deus e a nova destinação do homem segundo Nietzsche, in: LONGLOIS, L.; ZARKA, Y. C., Os filósofos e a questão de Deus, op. cit., p. 275-291.

27 Sobre o ateísmo de Sartre, ver: BARATA, A., Ateu, humanamente ateu - As razões de Sartre, in: XAVIER, M. L. L. O., A questão de Deus na história da filosofia, v. 1, Sintra 2008, p. 649-657. Ver também: INVITTO, G., Jean-Paul Sartre (1905-1980). "Deus não existe": a indemonstrabilidade de uma certeza, in: PENZO, G.; GIBELLINI, R., Deus na filosofia do século XX, op. cit., p. $409-420$.

28 Cf. PERINE, M., Deus no discurso filosófico, Síntese Nova Fase (Belo Horizonte), v. XX, n. 63, out.-dez. 1993, p. 477-497, republicado em: Eric Weil e a compreensão do nosso tempo. Ética, política, filosofia, São Paulo 2004, p. 227-263. 
qual tomo posição sobre o que chamei de o resultado do pensamento desse filósofo para a questão de Deus na filosofia. Não é possível retomar aqui o extenso debate que a filosofia de Heidegger provocou no interior da teologia cristã, travado tanto pelos entusiastas de primeira hora, que acreditaram encontrar na filosofia de Heidegger uma fonte de renovação da teologia, como pelos que se deram conta de que um pensamento que leva a lugar nenhum pouco ou nada tem a oferecer a uma forma de pensamento que se constituiu a partir da escuta da Palavra revelada na história. $^{29}$

Quero encerrar esta breve exposição sobre as raízes históricas do problema apontando para o impasse a que chegou o pensamento contemporâneo. Na avaliação de Lima Vaz,

o problema de Deus na filosofia clássica é o problema da prolação de um sentido absoluto nessa forma de linguagem que chamamos 'razão demonstrativa'. Essa possibilidade é contestada na filosofia contemporânea. As mais recentes discussões entre os filósofos sobre o problema de Deus se encontram sobretudo na questão: como é possível uma linguagem sobre Deus? Pode a linguagem humana suportar esse Sentido radical a que chamamos Deus? Como falar Deus ou como exprimir Deus na linguagem? Esse problema já tinha sido pressentido por Nietzsche, quando afirmou que enquanto não nos desfizermos da gramática construída segundo o modelo grego da proposição elementar de atribuição de um predicado a um sujeito, não vamos poder nos desfazer do problema de Deus ${ }^{30}$.

Como se vê, um destino do Sagrado ou de Deus no pensamento ocidental estava selado. Ao contrário do que ocorreu no pensamento medieval, no qual a prova da existência de Deus representava o momento racional da adesão pela fé, a prova cartesiana da existência de Deus passou a expressar o que Walter Schulz chamou de "vontade metódica de ateísmo". ${ }^{31}$ A prova cartesiana da necessidade de Deus pode ser chamada de parteira do ateísmo moderno e do silenciamento sobre Deus na filosofia contemporânea, pois "conduziu a metafísica moderna tanto ao

29 Ver, por exemplo, a extensa bibliografia sobre a questão no final de: KEARNEY, R.; O'LEARY, J. S. (Orgs.), Heidegger et la question de Dieu. Paris 1980. João A. Mac Dowell afirma que "[A] centralidade da problemática do divino no pensamento de Heidegger é hoje admitida pela maioria dos intérpretes". Cf. MAC DOWELL, J. A., A fé como compreensão intuitiva pessoal do sentido da realidade, Síntese - Revista de Filosofia (Belo Horizonte), v. XL, n. 128, set.-dez. 2013, p. 427-456, aqui p. 428 nota 1. Como comprovação Mac Dowell remete à obra de Günter Figal, da qual cita a seguinte afirmação: "Querer cancelar a Teologia do pensamento tardio de Heidegger equivaleria a amputá-lo de seu centro" (FIGAL, G., Gottesvergessenheit. Über das Zentrum von Heideggers Beiträgen zur Philosophie, in: Internationale Zietschrift für Philosophie, 2/2000, p. 177).

30 Cf. LIMA VAZ, H. C. de, O problema de Deus no pensamento contemporâneo, art. cit., p. 21 s.

31 Cf. SCHULZ, W., Le Dieu de la métaphysique moderne, trad. J. Colette, Paris 1978, p. 36. 
seu ponto mais elevado como à sua crise" 32 . Com efeito, o nervo da prova cartesiana é a prova da finitude humana, de modo que a infinitude de Deus fica na dependência da finitude do ser humano, pois só um ser que, pela ideia de Deus, conhece a sua finitude, é constrangido a pôr acima de si um ser necessário e perfeitíssimo que, em última análise, serve apenas para impedir que o "eu penso" tome o lugar de Deus, como ocorrerá logo depois. Dito de outro modo, a partir do momento em que Deus entrou no discurso filosófico "por necessidade", ele começou a ser expulso dele.

\section{O futuro do Sagrado}

O destino de Deus ou do sagrado na modernidade, como se viu, foi selado na grande revolução que deu nascimento aos tempos modernos. A "revolução antropocêntrica" iniciada por Descartes e por Hobbes teve os desdobramentos que estavam implícitos em sua certidão de nascimento. Com a "descoberta do homem", sistematizada na filosofia do sujeito, o problema de Deus passou a situar-se no terreno da subjetividade, que é o mesmo terreno no qual deveria ser fundada a nova ciência do mundo a ser construída pelo homem.

Com efeito, o nascimento da ciência moderna exigia uma nova forma de leitura dos fenômenos, marcada pela intervenção ativa do ser humano no estabelecimento de novos códigos de interpretação. Como sabemos, esses códigos deviam ser de natureza matemática, como bem viu Descartes e, também, um de seus mais célebres contemporâneos, Galileu. Construir códigos eficazes de leitura do mundo era o atributo fundamental do "eu penso" cartesiano.

De todos os pensadores posteriores, foi Nietzsche quem soube levar até o fim esse processo iniciado com a afirmação da subjetividade. A afirmação nietzschiana do "eu sou" é a consequência mais radical do "eu penso" cartesiano. Para Nietzsche, o "eu sou" é a afirmação da vida como processo de criação de valores. Nessa perspectiva, a única possibilidade de prolongar a vida como criação de valores consiste em negar o valor transcendente, que a tradição identificou com Deus. Mas isso só pode ser feito pelos que conseguirem superar tanto a heteronomia do "tu deves" como a autonomia do "eu quero", para alcançar a plenitude do "eu sou". Os que realizarem essa façanha serão os precursores o "homem do futuro" ou do homem além do homem.

Mas a referência a Nietzsche, obrigatória nesse contexto, deve ser extremamente cuidadosa, pois muitos traços da filosofia nietzschiana,

32 Cf. HENRICH, D., La prova ontologica dell'esistenza di Dio. La sua problematica e la sua storia nell'età moderna, trad. S. Carboncini, Napoli 1983, p. 24. 
quando lida sem preconceitos, deveriam abalar os lugares-comuns produzidos por uma leitura equivocada de um pensamento quase inclassificável, formulado intencionalmente de maneira intempestiva. Em texto extremamente denso sobre "O divino após a morte de Deus segundo Nietzsche", Paul Valadier chama a atenção para a distância entre "o ateísmo inquieto, atormentado, tenebroso de Nietzsche" e o "ateísmo tranquilo e conquistador dos racionalismos antropocêntricos". ${ }^{33}$ De fato, o universo religioso de Nietzsche tem claro parentesco com o pessimismo sombrio de Schopenhauer, a quem ele atribui um ateísmo "incondicional e leal", ${ }^{34}$ mas não indica nenhuma relação com a crítica racionalista de Feuerbach. A proclamação das mortes de Deus na tradição ocidental deve ser compreendida como crítica do monoteísmo, seja na versão do primeiro ateu, vale dizer, o Deus no Sinai, seja na versão de Paulo, com sua exaltação do crucificado, seja ainda na versão do homem louco do $\S 125$ de A gaia ciência, e da antecipação do futuro europeu no §343, no qual está inscrita a negação da vida e o triunfo do nada. ${ }^{35}$

Se ainda tem algum sentido falar em futuro do divino ou do sagrado, isso só poderá ocorrer se conseguirmos identificar alguma experiência humana que nos permita resgatar a transcendência sem que, para isso, seja preciso negar a imanência. Portanto, tratar-se-á de saber se podemos falar sensatamente de experiência do sagrado ou da experiência de Deus como experiência humana, demasiadamente humana...

Comecemos por refletir sobre o próprio conceito de experiência. $\mathrm{Na}$ linguagem comum, a palavra "experiência" designa pelo menos dois tipos de conteúdos. Ela pode ser concebida como busca de uma verdade e, nesse caso, será dirigida para a descoberta, para a prova e para a verificação. Experiência é, então, o conjunto de empreendimentos que visam à captação e à formulação de uma verdade nova por meio de uma pesquisa organizada com vistas a um fim. A trajetória que vai da pesquisa à posse da verdade é a experiência. Mas a palavra designa também o acolhimento e, ao mesmo tempo, a captação de uma realidade, isto é, a tomada de consciência de algo dado em mim. Nesse caso, ela não é dirigida à descoberta, à prova e à verificação, ela não é a busca de uma verdade, mas a vivência de uma realidade. Ela, então, não será o caminho

${ }^{33}$ Cf. VALADIER, P., O divino após a morte de Deus segundo Nietzsche, in: LONGLOIS, L.; ZARKA, Y. C., Os filósofos e a questão de Deus, op. cit., p. 293-306, aqui p. 294.

${ }^{34}$ Cf. NIETZSCHE, F., A gaia ciência, § 357.

${ }^{35}$ Segundo Valadier, a apologia politeísta de Nietzsche "pode ser compreendida, em primeiro lugar, na recusa de tudo o que representa o monótono-teísmo, redutor e finalmente ateu; compreende-se como equivalente a essa revivescência do divino que só poderá ocorrer com o fim do reino monoteísta; equivale ao fim da ilusão providencialista que ordena o mundo numa finalidade reconhecível e elimina, desse modo, a distância incomensurável do infinito". Cf. VALADIER, P., op. cit., p. 303. 
que vai da pesquisa à verdade, mas a própria posse de uma realidade dada, definindo-se pelo ato ou conjunto de atos que captam a realidade como presença. A experiência será, então, uma estrutura vivida, uma atividade de contato e até mesmo de comunhão. ${ }^{36}$

Se aceitarmos a definição de experiência, que contempla os dois sentidos anteriores, como "a face do pensamento que se volta para a presença do objeto", ${ }^{37}$ podemos dizer que toda experiência articula-se nos polos do sujeito e do objeto: o objeto na medida em que aparece e apresenta-se; o sujeito na medida em que é consciência que o penetra e penetra-se de sua presença. Daí decorre que a toda experiência corresponde uma linguagem de acordo com o modo da presença ao pensamento: existem coisas, existem outros e existe eu mesmo presentes ao meu pensamento.

$\mathrm{O}$ ato de voltar-se do pensamento para as coisas, para os outros e para si mesmo pode ocorrer tanto no plano empírico como no plano experimental. No plano empírico, isto é, imediato, temos o relacionamento ingênuo do sujeito consigo mesmo e com o mundo ao seu redor. No plano experimental, temos o sujeito manejando e coordenando os elementos de uma experiência para construir o universo da ciência. Nesse caso, trata-se de um relacionamento crítico com as leis de necessidade pelas quais os fenômenos impõem-se ao sujeito. ${ }^{38}$

Contudo, existe outro plano no qual a experiência é tomada em sua totalidade pessoal. É o plano no qual ocorre o relacionamento do sujeito com o outro, que a ele apresenta-se como interpelação e convocação de sua liberdade ao acolhimento desse outro, também como liberdade. Aqui, ao contrário dos dois primeiros planos, a liberdade é determinante, uma vez que só por ela o ser humano pode abrir-se para acolher o outro como sujeito livre, tecendo com ele o mundo da história e da cultura.

36 No âmbito de uma reflexão sobre a fé em Deus como intuição intelectual, João A. Mac Dowell recorre à noção de experiência intelectual como chave de compreensão da distinção entre as funções intuitiva e discursiva da razão: "Ao passo que a experiência intelectual consiste na compreensão imediata do sentido de algo presente na sua singularidade, o discurso, como pensar, re-presenta mentalmente as coisas, mediante uma imagem ou uma ideia. Uma coisa é conhecer por experiência, outra conhecer por reflexão pessoal ou por ouvir-dizer, fazendo uma ideia das coisas [...] A experiência, enquanto corresponde à função intuitiva da razão, é a captação do sentido pelo contato imediato com a realidade, ou melhor, pela identificação do intelecto conhecente com a realidade conhecida no seu sentido, ao passo que o discurso, o pensamento, a reflexão, se desenvolvem no âmbito interno da mente, como articulação de representações universais (ideias) ou singulares (imagens, recordações), apoiadas ou não nas intuições correspondentes". Cf. MAC DOWELL, J. A., A fé como compreensão intuitiva pessoal do sentido da realidade, art. cit., p. 444.

37 Cf. LIMA VAZ, H. C. de, A experiência de Deus, em: Experimentar Deus hoje, Petrópolis 1974, p. 76. Sobre a experiência religiosa, ver também MOUROUX, J., L'expérience chrétienne, Paris 1954, p. 13-56.

38 Cf. MOUROUX, J., op. cit., p. 24. 
Somente nesse plano, o ser humano encontra a plenitude do seu lugar, pois aqui ele situa-se no horizonte de um sentido que não é particular. O ser humano pode abandonar-se no dia-a-dia a uma série de condicionamentos naturais e culturais sem neles perder-se porque está aberto a algo que vai além deles. Ele pode fazer ciência porque capta o universal no particular, expressando-o coerentemente na linguagem das relações de necessidade. Mas, se é possível ao ser humano algum tipo de experiência religiosa, ela deverá ocorrer num plano que integre os três modos de presença da realidade à consciência, porque, se não for assim, a experiência não será humana.

Falar de experiência religiosa é falar de relação ao sagrado como objeto de amor e de reverência. Religião é relação ao sagrado, que pode ser chamado Deus, e que comporta necessariamente um aspecto social. Essa relação pessoal e social é também integral, posto que é toda a pessoa e, também, toda a comunidade que estão implicados na experiência religiosa. Dito de outro modo, existe experiência religiosa autêntica quando a pessoa capta-se em relação ao sagrado - Deus - sem excluir-se ao mundo e aos outros. Não há verdadeira experiência religiosa que não conduza a uma presença ao mundo e ao outro. Qualquer religião que servisse para tirar o ser humano do seu lugar no mundo seria um atentado à liberdade humana. Se há uma possibilidade de realizar a relação com o sagrado, com Deus, ela deve acontecer no aqui e agora da liberdade situada no mundo e com os outros.

A experiência humana que tem créditos para apresentar-se como autêntica experiência religiosa pode ser definida como a "experiência do sentido", que não se esgota numa das dimensões particulares da existência humana, mas ocupa o espaço total no qual elas desdobramse. ${ }^{39}$ Movemo-nos aqui no campo delicado das questões-limite, campo no qual toda conceptualização corre o risco de fracassar se pretender mais do que pode alcançar. Contudo, toda experiência humana deve poder ser traduzida em linguagem se quiser permanecer humana, isto é, se quiser permanecer no campo de significações e de sentido, próprio do ser humano.

A experiência religiosa é a experiência humana por excelência justamente porque é a experiência de um sentido radical. É claro que essa afirmação só parecerá sensata para quem não recusar uma significação positiva à mais radical das experiências humanas, que é a experiência da contingência. $\mathrm{E}$ o caminho que leva da experiência da contingência

39 Sobre a experiência religiosa como integrante de todos os componentes da experiência humana ver: MOUROUX, J., op. cit., p. 25-36; OTTO, R., Le sacré, Paris 1968; ELIADE, M., Le sacré et le profane, Paris, 1965; RABUT, O., L'expérience religieuse fondamentale, Tournai 1969. 
radical à experiência do Sentido radical deverá ser, negativamente falando, o caminho da recusa à absolutização de todo e qualquer sentido particular, por mais importante que seja, e, positivamente falando, o caminho da afirmação livre de um Sentido último sem o qual toda a realidade seria insensata.

Toda experiência humana está marcada, desde a origem, pelo sentido e só é humana porque está carregada de sentido. O ser humano surge no mundo como uma síntese de dois movimentos: o da intenção, pelo qual se abre ao horizonte infinito do ser, referindo-se, ao mesmo tempo, ao universal e ao aqui e agora; e o movimento da expressão, mediante o qual intenciona objetos exprimindo-os para si e situando-os no plano da consciência, que é o plano das significações. E, dado que o ser humano sempre se encontra inserido numa comunidade de sujeitos, a expressão do objeto para si é também a sua expressão para o outro. ${ }^{40}$

$\mathrm{Na}$ medida em que não renuncia à sua humanidade, o ser humano compreende-se no interior de um universo de sentidos. Mas, na mesma medida em que se compreende como criador de sentidos, ele descobrese como carente de um Sentido radical sem o qual todo o seu mundo fica exposto à insensatez e ameaçado por ela. A experiência mais primitiva do ser humano é a de apreender-se no interior de um mundo anteriormente dado, no qual ele recebe a sua existência como ser consciente e livre. É isso que se chama experiência humana da contingência.

Quando falo de experiência da contingência, refiro-me a um fato humano e, portanto, a algo que comporta um sentido, porque não haveria experiência da contingência se ela não fosse assumida no âmbito especificamente humano, que é o âmbito das significações e do sentido. Isso quer dizer que a contingência tem uma significação positiva para o ser humano. Para ele, ser contingente não se apresenta em primeiro lugar como uma falta, uma carência, mas como o fato de descobrir-se como liberdade dada a si mesma em um mundo que também lhe é dado. Fazer a experiência da contingência significa, para o ser humano, reconhecer o advento de sua liberdade; significa dar-se conta de que, no momento em que advém a si, a liberdade já se encontra provida de sentido e, portanto, é uma liberdade relativa ao sentido. A contingência não é o lado negativo de um ser que deveria ser a fonte de si mesmo. Ela é a positividade de um ser que advém em determinado momento. $O$ máximo que se pode dizer da contingência é que ela é o que teria podido não ser. Porém, dizer isso é, ao mesmo tempo, captar a sua força e a sua fraqueza. Mais ainda, é captar que a sua força consiste em compreender

40 Ver melhor esse ponto em LIMA VAZ, H. C. de, Ontologia e História, São Paulo 2001 (1ª ed. 1968), p. 247-278. 
a sua fraqueza. Fazer isso é reconhecer que a contingência é o único lugar em que o ser humano pode existir humanamente, isto é, no exercício da sua liberdade relativa ao sentido.

Considerar positivamente a contingência como um fato humano é reconhecer que a liberdade é algo que se constrói e que se recebe, não como um fato bruto, mas como fato relativo e, portanto, proveniente do sentido. Recusar a sua proveniência do sentido, recusar a sua relatividade ao sentido seria, para a liberdade humana, afirmar-se como um termo fora de qualquer relação e, portanto, como absoluto. Porém, afirmar a liberdade humana como absoluto é negar que ela seja humana e, portanto, relativa ao sentido. ${ }^{41}$

Justamente porque a liberdade humana só pode ser verdadeiramente humana na medida em que não recusa a compreensão relativa de si mesma, surge em seu horizonte a possibilidade da experiência de um Sentido absoluto. A negação de que qualquer pessoa ou coisa do mundo possa ser o sentido de tudo e a afirmação de que não somos os criadores últimos do mundo e de nós mesmos pode ser, ao mesmo tempo, o reconhecimento de um Sentido último. Assim, a experiência mais fundamental do ser humano pode ser a experiência de um Sentido radical a partir do qual tudo ganha consistência. Essa experiência, circunscrita pelos limites do mundo, do outro e do eu é, simultaneamente, a experiência de uma presença envolvente, que só pode ser compreendida analogicamente e que torna possível a compreensão de toda presença particular como presença sensata. O Sentido radical, desse modo, não é o absolutamente inefável. Se ele pode entrar na experiência humana, então pode-se falar dele, mesmo que unicamente com linguagem analógica e simbólica. Pode-se falar de uma experiência de Deus como sentido radical pela via da metáfora e, até mesmo, pela via da negação.

A experiência do Sagrado, como experiência religiosa do Sentido, por ser uma experiência humana, realiza-se na consciência e se expressa na linguagem, pois não há nada de verdadeiramente humano que não possa ser, de alguma forma, formulado na linguagem. Mas aqui a linguagem humana é posta em questão, porque o que ela deve expressar é o que ela capta além dela, isto é, o Mistério do Sentido último. Como é possível que o Absoluto seja dito na linguagem humana? Nesse ponto, a contingência humana e de tudo o que é humano descobre-se irremediavelmente impotente diante do Mistério. Mas é também nesse ponto que a contingência da linguagem humana encontra o seu único

${ }^{41}$ Retomo aqui as ideias expressas em: PERINE, M., Transcendência e mundo. Aproximação filosófica e visão cristã, Síntese Nova Fase (Belo Horizonte), v. XIX, n. 59, out.-dez. 1992, p. 481-485, republicado em: Eric Weil e a compreensão do nosso tempo, op. cit., p. 210-214. 
sentido. É preciso dizer e, no entanto, toda palavra não é mais que palavra humana, todas as representações não são senão determinações finitas do universo humano. Dizer Deus é, de certo modo, afirmar que Ele não pode ser posto pela nossa consciência. É verdade que existe sempre a possibilidade de não levar até o fim esse movimento de negação; existe sempre a tentação a pensar que Deus seria apenas diferente de nós, como se bastasse modificar mais ou menos as determinações a que a nossa inteligência acomoda-se para concluir que se trataria apenas de um simples desnível de ordem quantitativa, como se Deus pudesse ser o termo do nosso crescimento ou como se, por força de tender sempre ao infinito, em determinado momento pudéssemos possuí-lo. É necessário aceitar até o fim a exigência de negação para daí afirmar tudo de novo a partir da origem.

Deus não pode ser possuído por nós. Ele não é um bem superior, um ente supremo, cujo lugar, mesmo que fosse o primeiro, poderia ser marcado em nosso universo. Existe o abismo! E nós chegamos depois dele. Por isso, o movimento da negação nunca termina: nenhuma representação em si mesma nos diz nada de Deus. É necessário, para chegar a Deus, abandonar-se ao silêncio sonoro de que fala São João da Cruz, no qual ecoa, eternamente pronunciada, a Palavra original e originante a partir da qual toda palavra humana adquire sonoridade e sentido.

Não é o caso de assumir aqui uma fenomenologia do ato de fé, genericamente entendido como expressão da incerteza e do risco que se alojam nas raízes da posição do homem no mundo. ${ }^{42} \mathrm{O}$ ato de fé, pelo qual o homem compreende-se em Deus ${ }^{43}$ e afirma-o coerentemente tanto no discurso religioso como no discurso filosófico, não pode ser tomado como ato inteiramente cego e irrefletido. Uma reflexão filosófica sobre a natureza da fé, como propôs recentemente João A. Mac Dowell, indica que "a fé em Deus pode ser considerada como uma modalidade de fé radical, entendida aqui como o reconhecimento daquilo que dá sentido

42 Sobre essa perspectiva ver: WUST, P., Incertitude et risque, trad. G. du Loup, Neuchatel 1957. Segundo o autor, a sede insaciável de certeza, que está na origem da filosofia, liga-se à sede religiosa de salvação: "Para além das diferenças essenciais entre filosofia e religião, existe, em razão da unidade da natureza humana, certa convergência inelutável de uma com a outra, que não permite falar seja de uma sede de saber totalmente indiferente ao domínio religioso seja de um ato de fé inteiramente cego e irrefletido. É na questão absoluta do sentido e do insensato, tal como a põe a filosofia, que o caráter religioso de toda reflexão filosófica encontra sua expressão última. Eis porque a incerteza extrema do saber humano, tal como se esconde atrás da certeza filosófica mais elevada, já anuncia a situação metafísica de insegurança humana que, de resto, só se manifesta em toda a sua desesperadora obscuridade no nível da aspiração religiosa de salvação" (p. 19 s.).

43 Cf. BOUILLARD, H., Philosophie et religion dans l'oeuvre d'Eric Weil, Archives de Philosophie (Paris), n. 40, 1977, p. 543-621. 
à existência de cada um". ${ }^{44}$ Assim entendida, da fé nasce um laço pelo qual o homem vive a sua relação com Deus no âmbito do coração, isto é, do sentimento religioso como uma das dimensões constitutivas de seu modo de ser no mundo ${ }^{45}$, mas também como intuição compreensiva existencial, como fé radical que, segundo Mac Dowell, "tem o caráter de uma intuição pessoal do sentido último da existência e, portanto, constitui uma atividade da razão humana". ${ }^{46}$

Concluo esta reflexão com palavras de dois filósofos que, a meu ver, traduziram diferentemente em sua obra a compreensão da fé em Deus como fé radical e a sua vivência da fé como manifestação do sentimento religioso. O primeiro é contemporâneo nosso. Escreve Henrique de Lima Vaz sobre a experiência de Deus:

Em toda linguagem humana dotada de sentido em que uma realidade é dita, a Presença de Deus é igualmente dita, vem a ser, a experiência de Deus tem lugar na figura especificamente humana do discurso. ${ }^{47}$

O segundo foi contemporâneo de Descartes e de Hobbes. Escreve Blaise Pascal em seus Pensamentos:

É preciso saber duvidar onde é preciso, afirmar onde é preciso, submeterse onde é preciso. Quem não age assim não compreende a força da razão. Alguns falham contra esses três princípios, ou afirmando tudo como demonstrativo, desconhecendo-se na demonstração - ou duvidando de tudo, ignorando onde é preciso se submeter - ou submetendo-se a tudo, sem saber onde é preciso julgar. ${ }^{48}$

\section{Referências}

ARENDT, H. A condição humana. Rio de Janeiro 1991

BARATA, A. Ateu, humanamente ateu - As razões de Sartre. In: XAVIER, M. L. L. O., A questão de Deus na história da filosofia. Sintra, 2008. v. 1.

BOLINHAS, M. I. Uma releitura das cinco vias de Tomás de Aquino à luz do conceito de ser. In: XAVIER, M. L. L. O. A questão de Deus na história da filosofia. Sintra, 2008. v. 1.

44 Cf. MAC DOWELL, J. A., A fé como compreensão intuitiva pessoal do sentido da realidade, art. cit., p. 433.

45 Sobre o coração como lugar da experiência religiosa, ver: MESLIN, M., L'expérience humaine du divin. Fondements d'une anthropologie religieuse, Paris 1988, p. 217-226.

46 Cf. MAC DOWELL, J. A., A fé como compreensão intuitiva pessoal do sentido da realidade, art. cit., p. 448.

47 Cf. LIMA VAZ, H. C. de, A experiência de Deus, art. cit., p. 86.

48 Cf. PASCAL, B. Oeuvres complètes, Paris 1963, p. 523. 
BOUILLARD, H. Philosophie et religion dans l'oeuvre d'Eric Weil. Archives de Philosophie, Paris, 40 (1977), p. 543-621.

CORETH, E. Deus no pensamento filosófico. Trad. F. de A. Pinheiro Machado. São Paulo, 2009,

ELIADE, M. Le sacré et le profane. Paris, 1965.

FIGAL, G. Gottesvergessenheit. Über das Zentrum von Heideggers Beiträgen zur Philosophie. In: Internationale Zietschrift für Philosophie, 2 (2000).

GOYARD-FABRE, S. Introduction à le citoyen ou les fondements de la politique. Trad. S. Sorbiere. Paris, 1982.

HENRICH, D. La prova ontologica dell'esistenza di Dio. La sua problematica e la sua storia nell'età moderna. Trad. S. Carboncini, Napoli, 1983.

INVITTO, G. Jean-Paul Sartre (1905-1980). "Deus não existe": a indemonstrabilidade de uma certeza. In: PENZO, G.; GIBELLINI, R. Deus na filosofia do século XX. São Paulo, 1998.

KEARNEY, R.; O'LEARY, J. S. (Org.). Heidegger et la question de Dieu. Paris, 1980.

KOLAKOWSKI, L. Chrétiens sans église: la conscience religieuse et le lien confessionel au XVII ${ }^{\text {ème }}$ siècle. Paris, 1969.

KOLAKOWSKI, L. Metaphysical horror. Oxford, 1988.

LIMA VAZ, H. C. de. (1968). Ontologia e História. São Paulo, 2001.

LIMA VAZ, H. C. de. Escritos de filosofia VII. Raízes da modernidade. São Paulo, 2002.

LIMA VAZ, H. C. de. Religião e modernidade filosófica. Síntese Nova Fase, Belo Horizonte, XVIII, 53 (1991), p. 155.

LIMA VAZ, H. C. de. Escritos de filosofia IV. Introdução à ética filosófica I. São Paulo, 1999.

LIMA VAZ, H. C. de. Antropologia Filosófica I, São Paulo, 1991.

LIMA VAZ, H. C. de. Antropologia Filosófica II. São Paulo, 1992.

LIMA VAZ, H. C. de. O problema de Deus no pensamento contemporâneo. Síntese Nova Fase, Belo Horizonte, VIII, 23 (1981).

LIMA VAZ, H. C. de. A experiência de Deus. In: Experimentar Deus hoje. Petrópolis, 1974.

LONGLOIS, L. O fim das coisas e o fim da liberdade: a ideia de Deus na Crítica da razão pura. In: LONGLOIS, L.; ZARKA, Y. C. Os filósofos e a questão de Deus. Trad. L. P. Rouanet. São Paulo, 2009.

MAC DOWELL, J. A. A fé como compreensão intuitiva pessoal do sentido da realidade. Síntese - Revista de Filosofia, Belo Horizonte, XL, 128 (2013), p. 427-456.

MAQUIAVEL. Discursos sobre a primeira década de Tito Lívio. Livro I, cap. III.

MAQUIAVEL. O príncipe. cap. XVII.

MESLIN, M. L'expérience humaine du divin. Fondements d'une anthropologie religieuse. Paris, 1988.

MOUROUX, J. L'expérience chrétienne. Paris, 1954.

NIETZSCHE, F. A gaia ciência.

OTTO, R. Le sacré. Paris, 1968. 
PASCAL, B. Oeuvres complètes. Paris, 1963.

PENZO, G.; GIBELINI, R. Deus na filosofia do século XX. Trad. R. Leal Ferreira. São Paulo, 1998.

PERINE, M. Transcendência e mundo. Aproximação filosófica e visão cristã, Síntese Nova Fase, Belo Horizonte, XIX, 59 (1992).

PERINE, M. Deus no discurso filosófico. Síntese Nova Fase, Belo Horizonte, XX, 63 (1993).

PLATÃO. Leis. I, 626 D.

PRZYWARA, E. Augustin: passions et destin de l'Occident. Trad. P. Sécretan. Paris, 1987.

RABUT, O. L'expérience religieuse fondamentale. Tournai, 1969.

RICARD, M.-A. A morte de Deus e a nova destinação do homem segundo Nietzsche. In: LONGLOIS, L.; ZARKA, Y. C. Os filósofos e a questão de Deus. Trad. L. P. Rouanet. São Paulo, 2009.

SCHULZ, W. Le Dieu de la métaphysique moderne. Trad. J. Colette. Paris, 1978.

SEVE, B. La question philosophique de l'existence de Dieu. 2. éd. revue. Paris, 1997.

TOMÁS DE AQUINO. Suma Teológica. I, q. 2, a. 3.

TOMÁS DE AQUINO. In Boet. De Trin., 2, 3, 5.

VALADIER, P. O divino após a morte de Deus segundo Nietzsche. In: LONGLOIS, L.; ZARKA, Y. C. Os filósofos e a questão de Deus. Trad. L. P. Rouanet. São Paulo, 2009.

XAVIER, M. L. L. O. O argumento anselmiano entre continuadores e críticos. In: XAVIER, M. L. L. O. A questão de Deus na história da filosofia, Sintra, 2008. v. 1.

WEIL, E., Lógica da filosofia. Trad. Lara C. de Malimpensa, rev. téc. M. Perine. São Paulo, 2012.

WUST, P. Incertitude et risque. Trad. G. du Loup. Neuchatel, 1957.

\section{Endereço postal:}

Programa de Pós-Graduação em Filosofia PUC-SP

Rua Ministro Godoi, 969, $4^{\circ}$ andar, Bloco A, Sala 4E-16 - Perdizes

05015-901 São Paulo, SP, Brasil

Data de recebimento: 20/04/2014

Data de aceite: 30/04/2014 